Canadian Journal of Family and Youth, 13(3), 2021, pp. 397-402

ISSN 1718-9748@ University of Alberta

http://ejournals,library,ualberta.ca/index/php/cjfy

\title{
Listening Louder: Helping Children Through Their Parents' Divorce
}

\author{
Desiree Kastendieck, MacEwan University
}

\section{Introduction}

Although children are not isolated from adult life and problems, their opinions are often minimized and disregarded, notwithstanding the fact that many of these issues have an astronomical impact on their lives. Family life is extremely interconnected, with parents and children exerting bidirectional influences on each other. The stability of parental relationships is a key component of children's security. Thus, the challenges that come prior to divorce and continue throughout and after have a large impact on the physical, mental, and emotional well-being of children. One of the adversities that children encounter is living in an adult world but being considered inept at understanding and dealing with adult issues, even if they carry consequences for the child. While records of divorces and separations are incomplete, the available data indicates that the number of children affected by these processes are consistently high (Bagshaw, 2007, p. 451). As children are especially vulnerable in these times of transition and uncertainty, steps must be taken to adequately address possible problems and find solutions and ways to cope with the changes (Bagshaw, 2007, p. 451). Although generalized assumptions about the capabilities of children have impacted traditional methods of mediation, custody, visitation, and other components of divorce, research demonstrates that it is vital to listen to children individually to empower and support them so that their diverse levels of maturity and unique needs can be met during the uncertain and stressful time of parental divorce.

\section{Literature Review}

The reasoning behind divorce and separation has evolved over the years, but traces of the blame-centered approach of the past continue to affect policies that involve children. In the 1950s to 1970s, divorce was uniquely fault-based, which created stigma surrounding at least one of the parents and subsequently spread onto the children. Children were viewed as passive, broken, and dysfunctional units due to the tarnishing of the ideal family image. Currently, divorce is viewed less bleakly, instead seen for some as another chance for happiness, a fresh start, and sometimes as escape from domestic abuse. This shift has filtered into the attitude towards children of divorcees (Jolivet, 2011, p. 175). Instead of being written off, bolstering children's ability to cope with challenging circumstances by encouraging resilience has became the point of focus 
throughout the transitions that accompany parental divorce.

During a divorce, some vital ingredients that contribute to a smoother adjustment for children include having the ability to freely express their feelings, sense that their perspective is valued, and to be kept informed about future changes and the reality of the situation in general. Unfortunately, proceedings are often "dominated by the voices of adults, ignoring the findings that suggest that if children have a voice they are more likely to be happy with the decisions made" (Bagshaw, 2007, p. 453-454). Although many court systems preach the "best interests of the child" principle, there is frequently a gap between the idealized implementation of these concepts and their actual execution (Bagshaw, 2007, p. 454). When asked, children report that they want their preferences and thoughts concerning their living arrangements and their relationship with both parents to be considered. They do not wish to remain in the dark about their future as it fosters feelings of insecurity, whereas being trusted to handle things maturely gives the child a sense of control and importance during trying times (Birnbaum \& Saini, 2012, p. 406). Furthermore, when a child's independence is maintained and their perspective is valued, their capacity to endure hardships is heightened and "their self-esteem is bolstered" (Holt, 2018, p. 463). Simultaneously, decisions made concerning their situation are made with greater understanding that can help their quality of life and keep them safe (Holt, 2018, p. 463). Although these findings concerning children's desire to be involved in many facets of the divorce process are consistent, supported by research, and often have positive outcomes, attempting to lump all children together is counterintuitive.

To avoid falling prey to oversimplifying the issue of children's right to be heard, parents and those working with children need to be conscious and respectful of the fact that some children may not wish to have input or be involved, while others may lack the maturity to adequately understand and contribute. Although many children want the opportunity to express themselves openly, others may feel overwhelmed or simply do not wish to be consulted (Birnbaum, 2017, p. 152; Holt, 2018, p. 469). However, in general, children believe that they should have someone to talk to like their parents, friends, grandparents, counsellors, or even a judge to obtain further comfort and understanding of the situation (Bagshaw, 2007, p. 460). While engaging with children, "professionals are expected to consider factors such as the age of the child, the family structure, and the stage of the divorce" to ensure that generalizations about children are avoided (Wong et al., 2019, p. 420). In one study, researchers found that children over the age of seven could considered capable enough to provide input for decision making (Birnbaum \& Saini, 2012, p. 406). Although this study found a specific age of competence, children vary greatly, and one size does not fit all, thus children should be individually evaluated while also being supported during this time of instability and adjustment.

Balancing children's need to be active participants in the divorce with their need to be protected and not leaned on excessively can be a slippery slope. Due to the vulnerability of children, their needs and rights must be carefully integrated to avoid smothering them but also maintain their safety. Additionally, children realize that their voice is valued, but that they may not have the final word in decisions. Many children understand that possessing a voice is not synonymous with making a choice. They want to be treated with respect but the pressure of being the fixer upper of relationships or having the responsibility of dealing with heavy issues such as domestic violence are unfair burdens to be placed on young individuals. The dance between 
children's need to be genuinely involved without being torn apart by their parents is a delicate one. Another consideration that must be kept in mind is that children may be manipulated by parental pressure or lack the maturity to fully comprehend the situation (Birnbaum, 2017, p. 152). As a result, while children should be included beyond a superficial level through appropriate channels, their words must be evaluated with caution.

Children can participate and express themselves by talking to their parents, testifying in court or through video, an appointed child's counsel, a child custody and access assessment, a letter or affidavit from the child, mediation that includes the child, or through a judicial interview with the child (Birnbaum, 2017, p. 149). A qualitative study done by a university in Hong Kong examined the perspective of parents and children on the benefits and limitations of mediation (Wong et al., 2019, p. 418). Evidence demonstrates that children whose parents have gone through a divorce "manifest emotional, behavioral, health, and educational difficulties" (Wong et al., 2019, p. 419). Additionally, children's stress is compounded when conflict exists between the parents over arrangements after the divorce. Family mediation is one of the ways that attempts to alleviate some of this conflict and stress by employing an "unbiased and impartial mediator" who assists in identifying problems so that various options can be explored and pursued until a consensus is reached (Wong et al., 2019, p. 419). Mediation positively affects children as there is increased communication and cooperation between parents and decreased interparental strife. In addition, it can protect children from being used as leverage against the other parent. In this study, there was some confusion in certain children as they believed that mediators could repair their parents' marriage. Other children reported that they had a negative experience being involved in discussions between their parents as they felt trapped and uncomfortable watching their parents negotiate. Furthermore, some children felt torn and unwilling to express their genuine feelings for fear of upsetting a parent and chose instead to censor their responses (Wong et al., 2019, p. 428). This study illustrates that while including children often part of the process, their voices are effectively muffled because of the pressures that surround them.

The juxtaposition between children who experience security and contentment and those who keenly feel the lack of those elements post-divorce is clearly demonstrated by a phenomenological study whose participants were children. Researchers employed a semistructured interview approach to collect in depth qualitative information from 16 children aged 8 to 12 years old that explored their lived experience of shared time parenting. Common themes that emerged regarding feeling safe and happy included low levels of conflict between parents with the possibility of occasionally gathering the entire family in a cohesive and cooperative environment. For example, "Shane revels in the shared joy, particularly in his parents' capacity to engage together with their children in spontaneous light-hearted playfulness which erupts as he takes his first photograph" (Sadowski \& McIntosh, 2016, p. 74). The fact that his parents can interact in a positive way allows him to feel reassured. In contrast when children witnessed conflict and instability in interparental relations, these interactions caused distress and clouded over their experiences of shared time arrangements. For instance, Tabitha encountered the rigidness of rules imposed by the Court and enforced by argumentative parents that interfered with her ability to gain access to combined parental support. When she was called by her mother at her father's house, her dad interrupted the call and become angry and fought with her mother. As a result, Tabitha felt that her choices were constrained and felt upset that her parents were unable to get along. Another 
child, Giselle, described that she was in "a perpetual state of grief" because she missed having both of her parents physically available (Sadowski \& McIntosh, 2016, p. 81). Parents are not considered interchangeable to children and dividing their time between each parent equally did not rectify these sentiments. Some children in this study seemed to be able to adapt and "switch off" their longing for a specific parent, but other remained unable (Sadowski \& McIntosh, 2016, p. 82). Studies that explore individual feelings and situations that children encounter are key to understanding how parents, social workers, judges, lawmakers, and others who come into contact with children can work together to ensure that they have the best outcome possible as they struggle to navigate parental divorce.

In a divorce it can be easy for parents to forget that children are struggling with overwhelming emotions because of parents' own feelings, but it is vital to prioritize the wellbeing of their children. Research illustrates that children benefit from maintaining a relationship with both parents unless there is a risk of domestic abuse against the other partner or harm befalling the child. As such, developing a constructive relationship with the other parent that reduces hostilities while encouraging cooperation is helpful for children (Bala, 2015). Quality time invested in activities and being supportive parents has been associated with "a robust protective factor for children's mental health problems" (O'Hara et al., 2019, p. 690, 699). Some further suggestions for parents in creating a secure space for their children together include minimizing conflict, celebrating their children's accomplishments together with pride, enabling access to the absent parent without resentment, and building an integrated family that lives separately (Sadowski \& McIntosh, 2016, p. 78). Conversely, avoidance of alienating and undermining the other parent is necessary as those behaviours are emotionally damaging to children (Bala, 2015). Although consideration of the grief and stress a child is experiencing as their parents go through the process of a divorce is necessary, at times, positive elements emerge for the children of parents that go their separate ways.

Divorce that is advantageous for children can be a result of a few different circumstances, such as parental relationships that are full of conflict or domestic abuse. In certain situations, parental conflict can decrease after a divorce. There is evidence that supports that children benefit the most from divorce if their parents had violent marriages (Bagshaw, 2007, p. 452). Research demonstrates that "levels of child anti-social behavior, including lying, cheating and bullying, actually dropped following parental divorce for kids living in highly dysfunctional families" (Jolivet, 2011, p. 179). Unfortunately, in other cases children's chances of being exposed to domestic violence and potential homicide increases after parental separation (Bagshaw, 2007, p. 452). The potential for violence and personal danger in these high stress times reinforces the significance of proper procedures that ensure child safety.

Legislation in Canada concerning divorce and children's rights is severely outdated and is a hindrance to effectively protecting and helping children through the turbulence of parental divorce. Canada's Divorce Act focuses on the rights of the parents at the expense of children, allowing them to make assumptions about their offspring rather than asking for their input (Bala, 2015). Society has evolved since the enactment of these provisions, with the structure and understanding of the family shifting dramatically (Bala, 2015). The following except summarizes the direction that new policies should take: 
The reforms need to focus on parental responsibilities and children's relationships, rather than on parental rights. Divorce means the end of the spousal relationship, but it does not mean the end of the parent-child relationship, and there needs to be supports in place to allow for effective "co-parenting" relationships to develop. In some cases, it may be necessary for a judge to impose a plan on parents, or even stop the involvement of a violent or abusive parent in a child's life. However, in most cases, the law and family dispute resolution professionals should be assisting separated parents in the development of their own parenting plan. These plans should normally allow for significant involvement of both parents in the lives of their children that will evolve as children mature and circumstances change (Baha, 2015).

\section{Conclusion}

Children are often the true casualties when it comes to the dissolution of marriage between parents. Their voices have been muffled underneath the assumptions that they are uncapable of providing valuable input regarding their changing living and parental visitation arrangements. To combat this effect, children should be encouraged to articulate their opinions by being asked appropriate, child-centered questions with minimal parental influence. Even young children can express themselves and their perspectives should not be discounted. Their opinions should be considered equally as valuable as what the adults have to say. Most children want the opportunity to offer input that is weighted appropriately, but do not want their views to be determinative (Holt, 2018, p. 471). They understand that there are other factors at play and do not want the responsibility of making those hard choices alone. Children crave harmony in their lives and do not want to pick between parents but want flexibility and cooperation instead (Baha, 2015). In place of creating policies that drown out the voices of children, we are admonished to "listen louder" to as they are the "experts in their own lives" and individual beings in their own right (Holt, 2018, p. 463). 


\section{References}

Bagshaw, D. (2007). Reshaping Responses to Children When Parents are Separating: Hearing Children's Voices in the Transition. Australian Social Work, 60(4), 450-465. https://doiorg.ezproxy.macewan.ca/10.1080/03124070701671164

Bala, N. (2015). Bringing Canada's Divorce Act into the New Millennium: Enacting a ChildFocused Parenting Law. Queen's Law Journal, 40(2), 425-482.

Birnbaum, R. (2017). Views of the Child Reports: Hearing Directly from Children Involved in Post-Separation Disputes. Social Inclusion, 5(3), 148-154. https://doi.org/10.17645/si.v5i3.922

Birnbaum, R., \& Saini, M. (2012). A qualitative synthesis of children's participation in custody disputes. Research on Social Work Practice, 22(4), 400-409.

https://doi.org/10.1177/1049731512442985

Holt, S. (2018). A voice or a choice? Children's views on participating in decisions about postseparation contact with domestically abusive fathers. Journal of Social Welfare \& Family Law, 40(4), 459-476. https://doiorg.ezproxy.macewan.ca/10.1080/09649069.2018.1519653

Jolivet, K. R. (2011). The Psychological Impact of Divorce on Children: What is a Family Lawyer to Do? American Journal of Family Law, 25(4), 175-183.

O’Hara, K. L., Sandler, I. N., Wolchik, S. A., Jenn-Yun Tein, Rhodes, C. A., \& Tein, J.-Y. (2019). Parenting time, parenting quality, interparental conflict, and mental health problems of children in high-conflict divorce. Journal of Family Psychology, 33(6), 690703. https://doi-org.ezproxy.macewan.ca/10.1037/fam0000556

Sadowski, C., \& McIntosh, J. E. (2016). On laughter and loss: Children's views of shared time, parenting and security post-separation. Childhood: A Global Journal of Child Research, 23(1), 69-86. https://doi.org/10.1177/0907568215570072

Wong, M. M.-C., Ma, J. L.-C., \& Xia, L. L. (2019). A Qualitative Study of Parents' and Children's Views on Mediation. Journal of Divorce \& Remarriage, 60(6), 418-435. https://doi-org.ezproxy.macewan.ca/10.1080/10502556.2018.1558857 